\title{
Foraging Behavior of the Blue Morpho and Other Tropical Butterflies: The Chemical and Electrophysiological Basis of Olfactory Preferences and the Role of Color
}

\author{
Alexandra Sourakov, ${ }^{1}$ Adrian Duehl, ${ }^{2}$ and Andrei Sourakov ${ }^{1}$ \\ ${ }^{1}$ McGuire Center for Lepidoptera and Biodiversity, Florida Museum of Natural History, University of Florida, \\ Gainesville, FL 32611, USA \\ ${ }^{2}$ Center for Medical Agricultural and Veterinary Entomology, USDA-ARS, Gainesville, FL 32611, USA
}

Correspondence should be addressed to Andrei Sourakov, asourakov@flmnh.ufl.edu

Received 31 October 2011; Revised 9 January 2012; Accepted 18 January 2012

Academic Editor: Russell Jurenka

Copyright (C 2012 Alexandra Sourakov et al. This is an open access article distributed under the Creative Commons Attribution License, which permits unrestricted use, distribution, and reproduction in any medium, provided the original work is properly cited.

\begin{abstract}
Inside a live butterfly exhibit, we conducted bioassays to determine whether the presence of color would facilitate the location of attractants by the butterflies. It was found that color facilitated odor attraction in some species that feed on flowers (Parthenos silvia, Heraclides thoas, Dryas julia, and Idea leuconoe), but not in the exclusively fruit-feeding species, such as Morpho helenor, hence demonstrating that species with different natural diets use different foraging cues. Green, ripe, and fermented bananas were evaluated for their attractiveness to butterflies together with honey and mangoes. The fermented bananas were determined to be the most attractive bait, and the electrophysiological responses to their volatiles were studied in Morpho helenor and Caligo telamonius. During GC-EAD evaluation, fifteen different aliphatic esters, such as isobutyl isobutyrate, butyl acetate, ethyl butanoate, and butyl butanoate (both fermentation products and fruit semiochemicals) were shown to be detected by the butterflies' sensory apparatus located in the forelegs, midlegs, proboscis, labial palpi, and antennae. Legs, proboscis, and antennae of Morpho helenor and Caligo telamonius showed similar sensitivity, reacting to 11 chemicals, while labial palpi had a lower signalto-noise ratio and responded to seven chemicals, only three of which produced responses in other organs.
\end{abstract}

\section{Introduction}

Although the mechanisms involved in foraging for food have been studied in several model species of butterflies, there is still much unknown for this ecologically and physiologically diverse group of ca. 20,000 species. It is known that butterflies possess trichromatic vision, [1] which has a rather complex mechanism and evolutionary history [2]. It has been shown to play a role in the selection of potential mates [3], as well as in the location of adult food sources [4]. Butterflies possess the ability to discriminate even between fine variations of color, as it has been shown in Heliconius charithonia L. [5]. Many species have the capacity to learn to associate colors with a food source [6]. Papilio xuthus L., for example, was successfully trained to feed on a sucrose solution placed on a disk of a particular color and after a few such training sessions, the butterfly was able to select the color from an array of multi colored disks [7]. Butterflies can overcome their natural preferences, as in the case of newly emerged Heliconius, for which color stimulus can overtake scent in its importance after conditioning [8]. The same was found in monarchs, Danaus plexipus L., which show strong innate color preferences but can rapidly learn to associate colors with sugar rewards, doing so for noninnately preferred colors as quickly and proficiently as they do for innatelypreferred colors [9].

Although butterfly foraging is normally associated with feeding on nectar or pollen, many butterfly species, especially in the tropics, do not feed on flowers but instead are attracted to nitrogen-rich substances, such as feces and carrion, or feed on fermented fruit, tree sap, and other less colorful, but odorous substrates [10]. These food sources contain 
different volatile attractants than nectar, and species feeding on them are expected to use a different set of foraging cues than those used by purely flower-feeding species [11]. These rotting foods are characterized by low sugar concentrations and the presence of fermentation products (ethanol and acetic acid) [12]. However, the chemical composition of such rotting foods and the effects of these constituents on butterfly feeding behavior have rarely been investigated. As with other flower-visiting insects, the importance of visual and olfactory cues most likely varies with species, with each species having a unique favored combination of color cues and chemical compounds $[13,14]$.

Scent plays an important role in foraging, sometimes acting synergistically with color. In Vanessa indica Herbst, it was found that either scent or visual stimulus (artificial flowers used in experiments) acts as the important cue, depending on the particular color [4]. In another study, hawkmoths were attracted to flower models by either olfactory or visual cues, but only simultaneous exposure to both stimuli elicited feeding [15]. This reliance on perceiving both cues simultaneously is supported by neurological examinations of Lepidoptera [16], which revealed that activity in the mushroom bodies of the hawkmoth, Manduca sexta L., is influenced by both olfaction and vision during foraging. While testing color preferences in butterflies can be a relatively straight-forward task, identifying the specific compounds that they find attractive is often more difficult. Andersson and Dobson [17, 18] identified specific volatile compounds present in flowers commonly visited by butterflies and showed that there were antennal responses to most of these compounds. It was suggested that the presence of these compounds may be a result of adaptive pressure on flowers and host plants to specifically attract butterflies.

Not only do olfactory stimuli play an important role in locating food sources and potential mates, but they are crucial in locating the right host plants for oviposition. Plant odors, which are complex blends of dozens, if not hundreds of chemicals, are thought to have specific compounds, unique for different plants that are attractive to insects (e.g., [13]). It has been shown that electroantennographic responses can be elicited from butterflies with volatiles collected from the leaves of their corresponding host plants (e.g., [19-21]). Butterflies can be stimulated to lay eggs on certain plants by specific volatile compounds, as well as deterred from doing so by others (e.g., [22-27]). For instance, it was found that the oviposition behavior of female Papilio xuthus can be induced by methanol extracts of fresh leaves of Citrus plants [22], while hydroxybenzoic acid derivatives in a nonhost rutaceous plant deter both oviposition and larval feeding [28].

Considering the above studies, an extremely complex picture of butterfly sensory systems and of their foraging mechanisms emerges, it is clear that not only controlled experiments, but also field behavior and ecological studies involving a variety of species and scenarios, in combination with electro-antennographic analyses, are necessary, before we can fully understand the foraging strategies employed by Lepidoptera.
In the present study, by offering various combinations of color and scent, we examine how a diverse assemblage of tropical butterflies in a live butterfly exhibit responds to foraging cues. Red and yellow colors were chosen for the trials, as these colors are common in flowers, and they were most easily associated with a food source in a study of the swallowtail butterfly, Papilio xuthus [7]. The unique opportunity to examine foraging cues in a semicontrolled environment for multiple species of tropical butterflies with different ecologies and multiple individuals of different ages, sexes, and levels of foraging experience was presented by the Butterfly Rainforest facility at the University of Florida. Conducting experiments in these settings allowed the experiment to partially simulate a natural environment, while greatly increasing the chance of response due to a high density of butterflies and a variety of species present.

Following the initial bioassays, the most frequently observed species, Morpho helenor Cramer, was chosen for further electrophysiological examination. In this particular fruit-feeding forest species, color was expected to play little or no role in locating food, because rotten fruit on the forest floor is hardly discernible from the leaf litter. M. helenor must, therefore, rely on scent to find their food, and as a result, this species was expected to be particularly sensitive to olfactory stimuli. GC-EAD analyses were used to examine the antennal responses of $M$. helenor to the volatile compounds present in ripe banana, and another fruit feeding species, Caligo telamonius Felder, was used for comparison.

Previous studies showed that gustatory organs in insects often exhibit olfactory abilities [13] (and references within) and that olfactory receptors are present not only on antennae, but also on other appendages [29]. Hence, we decided to electrophysiologically examine not only the antennae, which are traditionally thought of as having an olfactory function, but also the proboscis, the foreleg, the midleg, and the labial palpi.

\section{Materials and Methods}

2.1. The Rainforest Bioassays. Bioassays were carried out in October-November 2009 and November-December 2010 in the Butterfly Rainforest exhibit facility located at the McGuire Center for Lepidoptera and Biodiversity, Florida Museum of Natural History, Gainesville, FL. The Butterfly Rainforest is a live butterfly exhibit consisting of a $600 \mathrm{~m}^{2}$ by $30 \mathrm{~m}$ high-screened enclosure with ambient conditions and hundreds of species of tropical plants providing shade and nectar. The ca. 2000 individual butterflies of ca. 50 species that fly in the Butterfly Rainforest include swallowtails (Papilionidae), brush-footed butterflies (Nymphalidae), and sulphurs (Pieridae) (see http://www.flmnh.ufl.edu/butterflies/guide/ for details). The butterflies mostly feed on nectar from flowers, such as Pentas lanceolata (Rubiaceae) and Symphyotrichum dumosum (Asteraceaea). Some butterflies, however, such as Morpho and Caligo species, feed exclusively on fermenting fruit (mangoes and bananas) which are provided regularly on trays. 
2.1.1. Bioassay I. Five separate replications were performed in the Butterfly Rainforest between October 30 and November 13, 2009. The trials were conducted for four hours between $13.00 \mathrm{~h}$ and $17.00 \mathrm{~h}$ on each occasion (RH: $68-85 \%$, temp.: $21-30^{\circ} \mathrm{C}$ ). Five cardboard landing pads covered with red $(650 \mathrm{~nm}$ wave length, $49 \%$ reflectivity), yellow ( $570 \mathrm{~nm}$ wave length, $35 \%$ reflectivity), or black ( $7 \%$ reflectivity) paper were placed simultaneously on the railings ca. $1 \mathrm{~m}$ above the enclosure floor. Three of the pads (red, yellow and black) were covered with $10 \%$ honey solution, while two of the landing pads (red and yellow) were used as controls and were left unbaited. The landing pads were placed so that each pad received approximately the same amount of sunlight. The positions of the landing pads were rotated at random every hour to prevent butterflies from memorizing a specific location of bait. Honey solution was reapplied with a sponge every $30 \mathrm{~min}$. Butterfly landings (physical contact with a circle, either by direct landing or by landing near the pad and then crawling onto it) were recorded and photographed.

2.1.2. Bioassay II. In 2010, a second bioassay was conducted to determine which bait (mango, banana (green, ripe, and fermented), or honey) was the most attractive to M. helenor. Four separate replications were performed between October 25 and November 29, 2010. The trials were conducted between $16.00 \mathrm{~h}$ and $17.00 \mathrm{~h}$ on each occasion (RH: $62-79 \%$, temp.: $20-29^{\circ} \mathrm{C}$ ).

In this bioassay, the butterflies were simultaneously offered a choice between eight "scent stations" which emitted scents of mango, banana, or honey. The control station contained no bait. Scent stations were comprised of a glass jar ( $7 \mathrm{~cm}$ tall, $4 \mathrm{~cm}$ in diameter) that contained the bait placed under an upended plastic cup ( $12 \mathrm{~cm}$ tall, $8 \mathrm{~cm}$ in diameter) with holes punctured in the bottom to allow scent to escape the cup (Figures 3(a)-3(c)). Each type of bait included one red ( $650 \mathrm{~nm}$ wave length, $49 \%$ reflectivity) and one clear cup to test for possible color preference. The distance from the holes to the cups with the attractants was greater than the proboscis length of a butterfly, preventing them from feeding. The bioassay was designed so that butterflies were unable to make physical contact with the attractants/bait and were only able to land individually on each "scent station." Thus, in Bioassay II, we were able to eliminate possible factors of gregarious behavior and conditioning from our experimental design (perceived shortcomings associated with Bioassay I). The scent stations were placed on the same railing as in Bioassay I and their positions were randomly rotated every 30 min. Butterfly landings (physical contact with a cup) were recorded by species for each scent station. Separately, green banana bait was compared with fermented banana. Landing data in Bioassay 1 were compared with a Mann-Whitney statistical test using PAST software. ANOVA was also used when analyzing the results of Bioassay 2.

2.2. Banana Volatile Collection and Analysis. Procedures described in Sections 2.2 and 2.3 were conducted at the

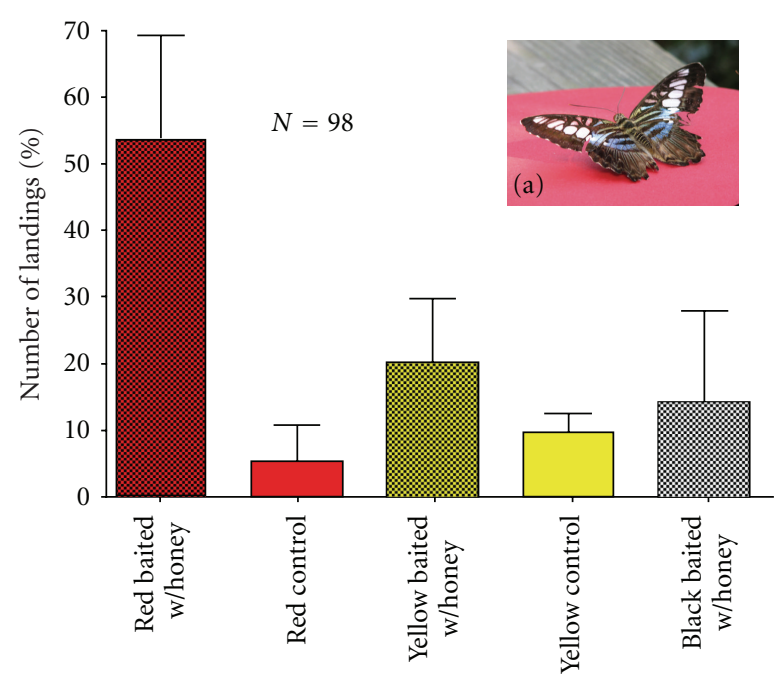

Type of landing platform

Figure 1: Bioassay I. The Clipper butterflies, Parthenos sylvia (a), showed a strong preference for the red baited landing platforms when offered an array of other choices.

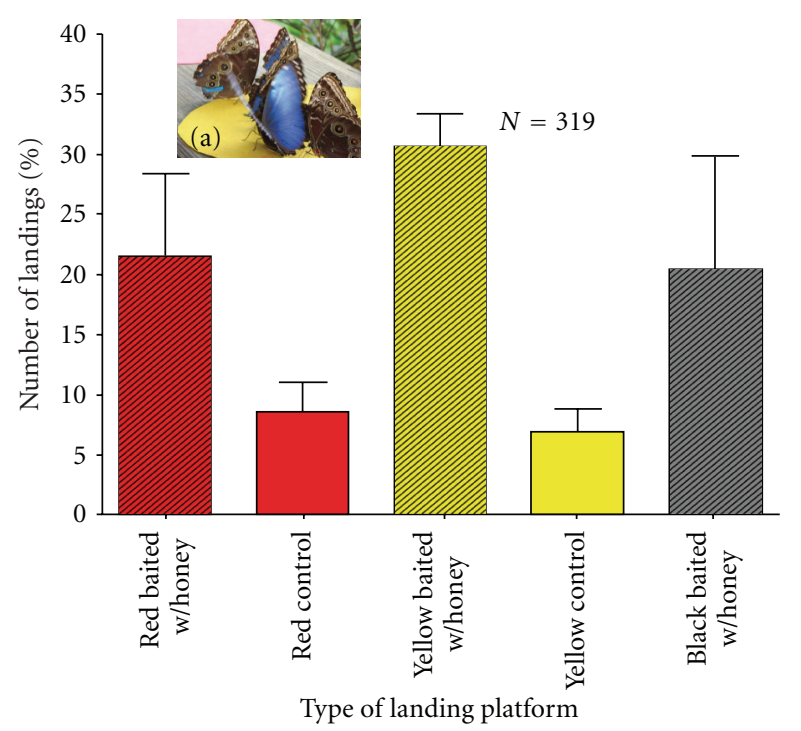

Figure 2: Bioassay I. Blue Morpho butterflies, Morpho helenor (a), showed a strong preference for baited landing platforms compared to nonbaited platforms.

Chemistry Research Unit of the Center for Medical, Agricultural and Veterinary Entomology (USDA-ARS, Gainesville, $\mathrm{FL})$.

2.2.1. Volatile Collection. To obtain fermented banana, the unpeeled ripe bananas were cut into thin pieces and placed into a resealable plastic bag, which was stored outside for 6 days (RH: $80 \%$; temp: $31^{\circ} \mathrm{C}$ ), thus inducing the fermentation process. Banana volatile collections were conducted using dynamic headspace adsorption method. Bananas were sliced and placed on a sheet of aluminum foil, which was put into a $1.7 \mathrm{~L}$ glass volatile collection chamber (Agricultural 
TABLE 1: Butterfly species that visited landing platforms during Bioassay I.

\begin{tabular}{|c|c|c|c|c|}
\hline Scientific name & Common name & Diet & Origin & Number of Landings \\
\hline Morpho achilles & Banded Morpho & fruit & Central America & 1 \\
\hline Hamadryas amphinome & Blue Cracker & fruit & Central America & 3 \\
\hline Morpho helenor & Blue Morpho & fruit & Central America & 319 \\
\hline Parthenos sylvia & Clipper & flower/fruit & Philippines & 98 \\
\hline Neptis hylas & Common Sailor & fruit & Southeast Asia & 14 \\
\hline Hypolimnas bolina & Great Eggfly & flower & Southeast Asia & 10 \\
\hline Catonephele mexicana & Grecian Shoemaker & fruit & Central America & 4 \\
\hline Eueides vibilia & Vibilia Longwing & flower & Central America & 3 \\
\hline Kallima paralekta & Indian Leaf & fruit & Southeast Asia & 1 \\
\hline Dryas julia & Julia & flower & Florida & 14 \\
\hline Cethosia cyane & Leopard Lacewing & flower/fruit & Southeast Asia & 2 \\
\hline Parides iphidamas & Pink Cattleheart & flower & Central America & 1 \\
\hline Heraclides thoas & Thoas Swallowtail & flower & Central America & 13 \\
\hline Papilio pilumnus & Three-tailed Swallowtail & flower & Central America & 1 \\
\hline Idea leuconoe & Tree Nymph & flower & Southeast Asia & 17 \\
\hline Myscelia cyaniris & Tropical Blue Wave & flower & Central America & 4 \\
\hline Morpho polyphemus & White Morpho & fruit & Central America & 1 \\
\hline Heliconius charithonia & Zebra Longwing & flower & Florida & 1 \\
\hline
\end{tabular}

(Photos of these and other species found in the Butterfly Rainforest can be viewed at http://www.flmnh.ufl.edu/butterflies/guide/.)

Research Systems, Gainesville FL). Clean air passed into the chamber through Teflon tubing (Cole Parmer, Vernon Hills, IL); air flow was regulated with a flow meter (Alborg, Orangeburg, NY) set to $110 \mathrm{~mL} / \mathrm{min}$. The air passed over the fruit before being drawn out with a vacuum (also regulated with a flow meter). As the air was pulled from the chamber, it passed through a filter containing $50 \mathrm{mg}$ Super Q (Alltech, Nicholasville, KY) which captured volatiles. Volatile collections were conducted for $2 \mathrm{hrs}$. To elute volatiles trapped in the filter, $200 \mu \mathrm{L}$ of methylene chloride (SigmaAldrich, St. Louis, MO) were added to filter and pushed through with nitrogen gas into a $1.5 \mathrm{~mL}$ glass vial (SunSri, Rockwood, TN) with a $0.25 \mathrm{~mL}$ conical insert (Sun-Sri, Rockwood, TN). The volatiles collected for GC-EAD did not have an internal standard added. Those for identification and quantification had $5 \mu \mathrm{L}$ of $80 \mathrm{ng} / \mu \mathrm{L}$ nonyl acetate (SigmaAldrich, St. Louis, MO) solution in methylene chloride added before the filter was eluted. Samples were stored at $-80^{\circ} \mathrm{C}$ until they were used for assays.

2.2.2. Volatile Bioassay. Volatiles were tested in the Butterfly Rainforest by deploying $10 \mu \mathrm{L}$ with a syringe onto $5.5-\mathrm{cm}$ qualitative filter paper and observing the number of butterfly landings for $1 \mathrm{~h}$. Volatiles were reapplied every $30 \mathrm{~min}$. It was determined that they maintained the same level of attraction for the butterflies as fermented banana.

2.2.3. GC-MS Analyses. Chemical analyses and quantifications were conducted using both gas chromatographymass spectroscopy (GC-MS) and gas chromatography-flame ionization detection (GC-FID). Volatile chemical identities determined by GC-MS analyses (Figure 4) were confirmed by analysis of synthetic standards, by comparing retention times and MS fragmentation patterns for 2-methylbutyl acetate, butyl acetate, ethyl butyrate, hexyl acetate, butyl butyrate, and propyl acetate. Other chemicals were identified from their MS fragmentation patterns using ChemStation software (Agilent Technologies, Santa Clara, CA) and the NIST mass spectral library (NIST, Gaithersburg, MD): all chemicals matched at least $90 \%$. For GC-FID, samples in extracts were injected $(1 \mu \mathrm{L})$ in the splitless mode, injector purge at $1 \mathrm{~min}$. Helium was used as a carrier gas at a linear flow velocity of $20 \mathrm{~cm} / \mathrm{sec}$. The oven was held at $35^{\circ} \mathrm{C}$ for $5 \mathrm{~min}$ and then increased at $5^{\circ} \mathrm{C} / \mathrm{min}$ to $75^{\circ} \mathrm{C}$ and then $10^{\circ} \mathrm{C} / \mathrm{min}$ to a final a temperature of $230^{\circ} \mathrm{C}$. EI GC-MS analyses of extracts from Super Q filters were conducted using a Hewlett Packard HP6890 GC interfaced to an HP5973 MS and equipped with a $30 \mathrm{~m} \times 0.25 \mathrm{~mm}$ ID HP1 Column. The ion source temperature was $220^{\circ} \mathrm{C}$ and the transfer line was held at $240^{\circ} \mathrm{C}$. The GC oven was operated under the same conditions as for the GC-FID analyses.

\subsection{Gas Chromatography Electroantennographic Detection.} The coupled GC-EAD was conducted using a GC-FID (Hewlett Packard HP 6890 equipped with an Alltech EconoCap, EC-1 $30 \mathrm{~m} \times 0.25 \mathrm{~mm}$ Column), a heated transfer line and humidified cool air to introduce the separated chemicals to the insect organ. Conditions of chromatographs were the same as those used for the previously described GC-FID analyses. The GC was connected to both a flame ionization detector (FID) and an electroantennographic detector (EAD) (Syntech, The Netherlands), with a split ratio of $1: 1$. The EAD column discharged into a glass tube, and a humid air stream chilled and transported the volatile compounds to the organ situated on the electrode. 


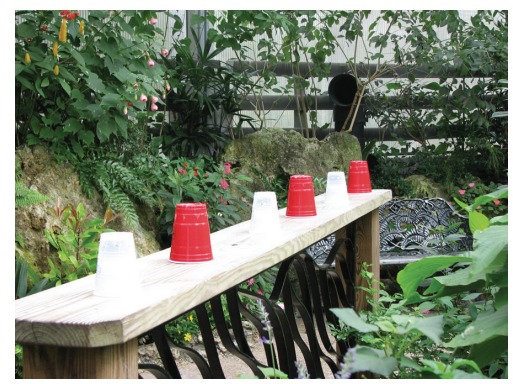

(a)

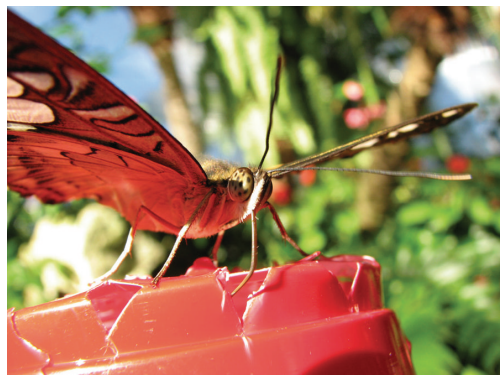

(b)

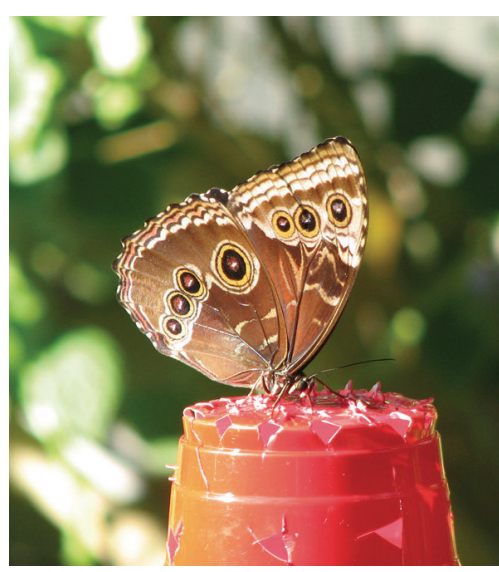

(c)

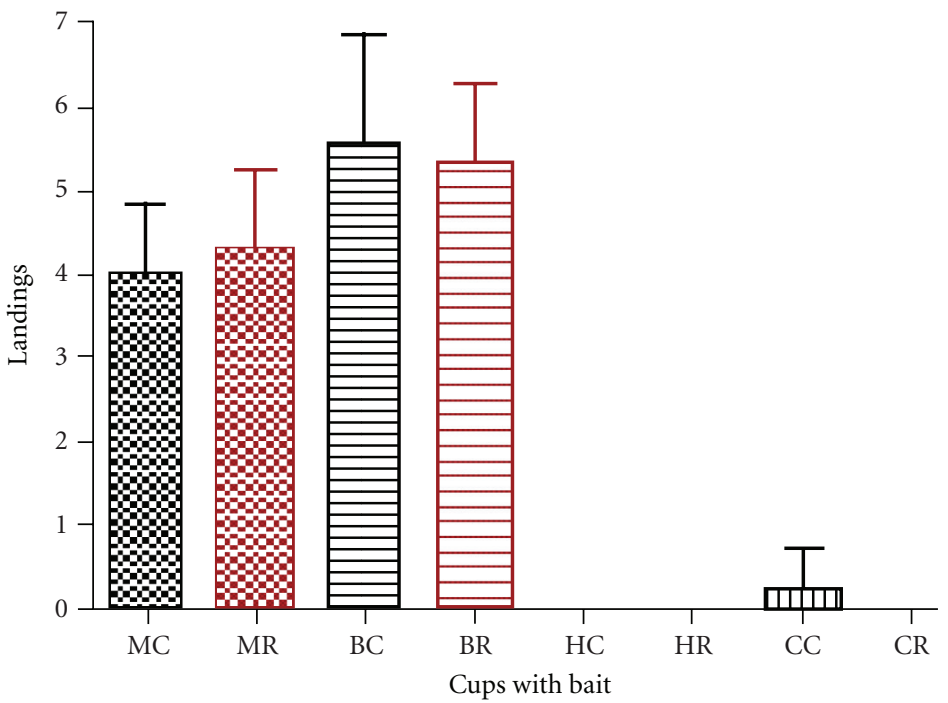

(d)

FIGURE 3: Bioassay II. (a-c) Scent stations attracting butterflies in the Butterfly Rainforest. (d) Graph showing the frequency of landings by Morpho helenor on bait stations emitting smells of mango (M), banana (B), or honey (H). C: clear cups, R: red cups. CC and CR are control (no bait) stations.

Labial palpi, antenna, legs, proboscis, and forelegs (SEMs of these organs are shown in Figure 6) were procured from two live female Morpho helenor. In total, four midlegs, four forelegs, four antennae, and two proboscises were examined. The antenna, proboscis, legs, and forelegs were cut in half. Electrode Gel (Spectra 360, Parker Labs, Fairfield, NJ) was spread evenly on both sides of a PRG-2 probe (Syntech, Netherlands). Under a microscope, both halves of the organ were placed $2 \mathrm{~mm}$ apart on the electrode. The ends of both halves of the organ were covered with the electrode gel, so that only the middle remained uncovered and suspended between the two sides of the electrode. When preparing the labial palpi for the GC-EAD analysis, they were not cut in half and were placed onto a $4 \mathrm{~mm}$ wide probe. Similar techniques were applied to a single female individual of an Owl butterfly, Caligo telamonius Felder. Once this was set up, the probe was attached to an Intelligent Data Acquisition Controller, IDAC-232 (Syntech, Netherlands) that interfaced with a personal computer running EAD2000, Version 2.6 (Syntech, The Netherlands), to record both the output from the FID and the antenna. This enabled the pairing of insect antennal responses and the corresponding FID signals.
2.4. Scanning Electron Microscopy. Morphology of the electrophysiologically examined organs was illustrated in $M$. helenor using a Scanning Electron Microscope (model JOEL JSM-5510-LV) at the Florida State Collection of Arthropods.

\section{Results}

3.1. Bioassay I. A total of 507 landings by 18 species were recorded (Table 1). Clipper, Parthenos sylvia, which landed a total of 98 times (19\% of all landings) showed a strong preference for the red baited circle $(P<0.02)$ (Figure 1). Hence, in P. sylvia, the combination of the red color and the scent of honey produced the strongest response. Similarly, Heraclides thoas (L) (Papilionidae), Dryas julia (Fabricius), and Idea leuconoe Erichson (Nymphalidae), which, in combination, accounted for $9 \%$ of the landings, also showed a statistically significant preference for the red baited pad. For $H$. thoas, $85 \%$ of the landings $(N=13)$ were on the red baited pads; $D$. julia landed on red baited pads $100 \%(N=14)$; I. leuconoe$71 \%(N=17)$. 


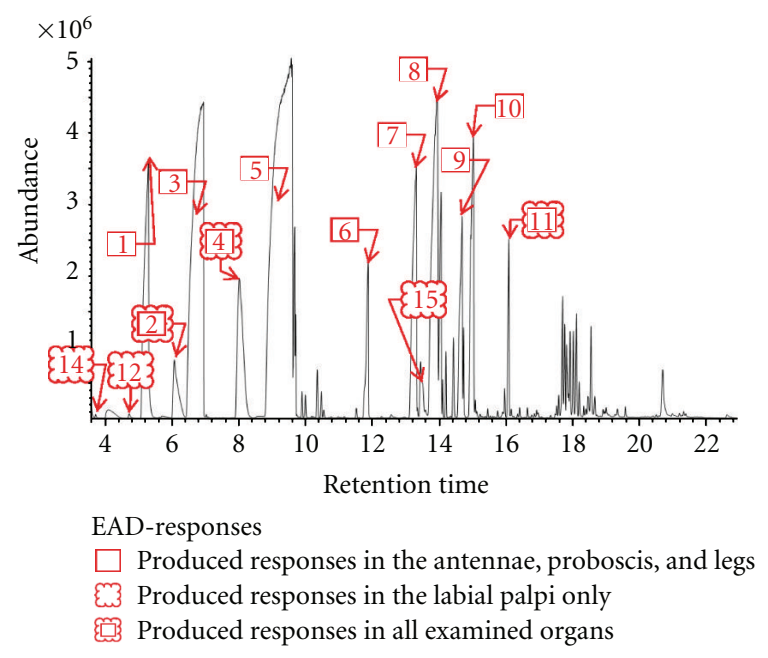

FIGURE 4: GC-MS chromatograms of volatiles collected from fermented banana. Numbered compounds produced EAD-responses in the antennae, proboscis, forelegs, midlegs, and labial palpi of Morpho helenor and Caligo telamonius (compound no. 13, propyl acetate, was determined using GS-FID). For compound names, see Table 2.

Morpho helenor was the dominant species in our study, responsible for $63 \%$ of all landings $(N=319)$. For this species, the three baited pads were significantly more attractive than the nonbaited pads $(P<0.02)$, but no significant color preference was found (Figure 2).

3.2. Bioassay II. In the second bioassay, which was primarily aimed at determining the preferred food source of Morpho helenor, banana was found to be more attractive than mango, honey, and the control. To test the significance of color in the foraging of this species, red and clear cups were offered for each type of bait. No significant difference $(P>0.05)$ was found in the color preferences of Morpho helenor: it landed as frequently on red cups as it did on the clear cups (Figure 3(d)), supporting the results of Bioassay I. Green, ripe, and fermented bananas were tested for their attractiveness, and the latter were found to be significantly more attractive.

3.3. GC-EAD Analyses. Morpho helenor showed electrophysiological responses to a total of fifteen compounds (all esters) from the fermented banana volatiles (Figure 5, Table 2). Four of the five organs analyzed (proboscis, foreleg, midleg, and antenna) reacted with similar intensity to the same 11 chemicals (Figure 5). The labial palpi reacted to three of these chemicals as well as four other chemicals, which did not elicit response from proboscis, legs, or antenna, and the responses were weaker. A single Owl butterfly, a female of Caligo telamonius, was analyzed in the same manner in which we studied Morpho helenor, and the EADresponses of its organs were also similar. In Figure 4, we provide a chromatogram from fermented bananas to show the presence and abundance of attractive compounds. The chromatograms obtained initially from green, ripe (readyto-eat stage), and fermented bananas indicate that number and abundance of volatile compounds increased as the fruit aged and the fermentation is responsible for a number of the compounds, absent in green fruit. The electrophysiological responses to these volatiles in Morpho helenor and Caligo telamonius (Figures 5(a) and 5(b)) indicate that different aliphatic esters, such as isobutyl isobutyrate, butyl acetate, ethyl butanoate, and butyl butanoate, which are both fermentation products and fruit semiochemicals, produce responses in the olfactory organs of fruit-feeding butterflies. Some of these compounds, such as 1-Methylbutyl acetate (aka isoamyl acetate) are responsible for banana odor in banana oil, while others, such as isobutyl isobutyrate or ethyl 2-methylpropanoate, are the products of fermentation.

3.4. Morphology. The examination of legs, proboscis, labial palpi, and antennae using SEM showed the presence of sensilla on all of these organs (Figure 6). Organs other than proboscis possess long sensilla that have been described as olfactory [29]. We also illustrate gustatory sensilla located on proboscis on the midproximal part of galeae (Figure $6(\mathrm{k})$ ). These are possibly responsible for both gustatory and olfactory functions as is the case with sensilla styloconica found on proboscis of cabbage armyworm [30].

\section{Discussion}

Bioassay I showed that different species are likely to exhibit different foraging behaviors and that generalized conclusions should not be drawn from experiments conducted on one or two species. The fact that flower-feeding butterflies Parthenos sylvia, Heraclides thoas, Dryas julia, and Idea leuconoe showed a preference for a specific color (red) during these bioassays confirmed that color cues are important for butterflies during foraging. Many flowers in the Butterfly Rainforest are red and the nectar-feeding butterflies could have learned to associate this color with the nectar reward. Repeated landing on the red baited circles and obtaining the honey solution reward could have further conditioned these butterflies. 
TABLE 2: Chemical volatile compounds collected from fermented banana and the presence $(+)$ of EAD-responses to these compounds in various appendages of Blue Morpho butterfly (Morpho helenor).

\begin{tabular}{|c|c|c|c|c|c|c|}
\hline Number in Figure 4 & Volatile compound & Antenna & Mid-leg & Proboscis & Labial palp & Foreleg \\
\hline 1 & 2-Methylpropyl acetate & + & + & + & & + \\
\hline 2 & Ethyl butanoate & + & + & + & + & + \\
\hline 3 & Butyl acetate & + & + & + & & + \\
\hline 4 & 1-Methylbutyl acetate & + & + & + & + & + \\
\hline 5 & 3-methylbutyl acetate & + & + & + & & + \\
\hline 6 & Isobutyl isobutyrate & + & + & + & & + \\
\hline 7 & Butyl butanoate & + & + & + & & + \\
\hline 8 & Hexyl acetate & + & + & + & & + \\
\hline 9 & 1-Methylhexyl acetate & + & + & + & & + \\
\hline 10 & Butyl 3-methylbutanoate & + & + & + & & + \\
\hline 11 & Pentyl pentanoate & + & + & + & + & + \\
\hline 12 & Ethyl 2-methylpropanoate & & & & + & \\
\hline 13 & Propyl acetate & & & & + & \\
\hline 14 & Isopentyl formate & & & & + & \\
\hline 15 & Hexenyl acetate & & & & + & \\
\hline
\end{tabular}

The outcome of this assay supports previous studies (e.g., [4, $8,31])$, which have found that a combination of stimuli are necessary to elicit feeding response and that some butterflies have the ability to discriminate between colors.

While Parthenos sylvia, Heraclides thoas, Dryas julia, and Idea leuconoe greatly preferred the red baited circles, the fruit-feeding Morpho helenor did not discriminate between colors and equally visited red, yellow, and black baited circles, while avoiding the unbaited controls (regardless of color). In the Butterfly Rainforest, where M. helenor are fed yellow mangoes and bananas, we expected a preference for yellow baited circles, yet this species exhibited no such preference. In the darkness of the forest floor, where M. helenor forage naturally for rotting/fermenting fruit that have fallen from the canopy, visual cues are reduced. Hence, the ecology of this species corresponds with our findings: $M$. helenor relies more upon volatile cues than color when foraging.

EAD-analyses performed on various organs of Morpho helenor and Caligo telamonius suggest that rotting fruit volatiles can be perceived not only by sensilla located on antennae (as has been traditionally thought), but also by those located on the proboscis, labial palpi, and legs. It is possible that the olfactory receptors covering the legs, antennae, proboscis, and labial palpi are simultaneously sending messages to the butterfly's brain, hence increasing the magnitude of the signal. This supports previous studies which indicated the possible olfactory role of the proboscis ([30] (and references within)). Previously proposed functions of the labial palpi include the detection of sexual pheromones, attunement to adult food sources, stimulants for migration, a shield for the proboscis, and wipers for cleaning the eyes of the butterfly [29]. The present study indicates that labial palpi are equipped to detect some of the volatile chemicals present in adult food sources. However, the array of chemicals perceived by the palpi is different from the array perceived by antennae, legs, or proboscis, with an overlap of only three compounds (out of 15 total, Table 2).
Such a distribution of different functions between organs might contribute to the efficiency of olfactory processing in butterflies.

When butterflies are foraging for fermenting fruit, they use cues from the fruits themselves and from the fermentation products produced by the rotting fruit [11]. This notion has been confirmed by the present study: Morpho helenor reacted to several compounds that are products of fermentation (e.g., isobutyl isobutyrate; ethyl 2-methylpropanoate), as well as several compounds that are commonly found in fruit (e.g., butyl acetate; ethyl butanoate; butyl butanoate) and are responsible for fruity odor. When we initially compared the volatiles released by unripe, ripe, and fermented banana using GC-MS, it was generally observed that the abundance of the volatile compounds increased as the fruit fermented. It was also observed that the GC-MS of fermented banana volatiles contained compounds that are not present at all in the chromatograms of green and ripe bananas. This explains why fruit-feeding butterflies are not attracted to unripe fruit: to locate their food source, they require volatile compounds associated with both fruit and fermentation. Fermentation cues must also play a role when butterflies are locating other food sources, such as rotting fish, dung, and carrion.

The specific chemistry of banana volatiles and the responses these chemical compounds elicit in Morpho helenor and Caligo telamonius are the most analytical and controlled parts of our study, and yet they may also be the most ambiguous when it comes to drawing conclusions. For instance, although we determined that the most abundant compound in the fermented banana volatiles that $M$. helenor and C. telamonius reacted to was 3-methylbutyl acetate, this does not necessarily mean that it is the banana semiochemical that attracts butterflies, as we do not know what role the abundance of a chemical plays. It is known that semiochemicals, such as pheromones, do not need to be present in great volume to trigger a response [32]. 


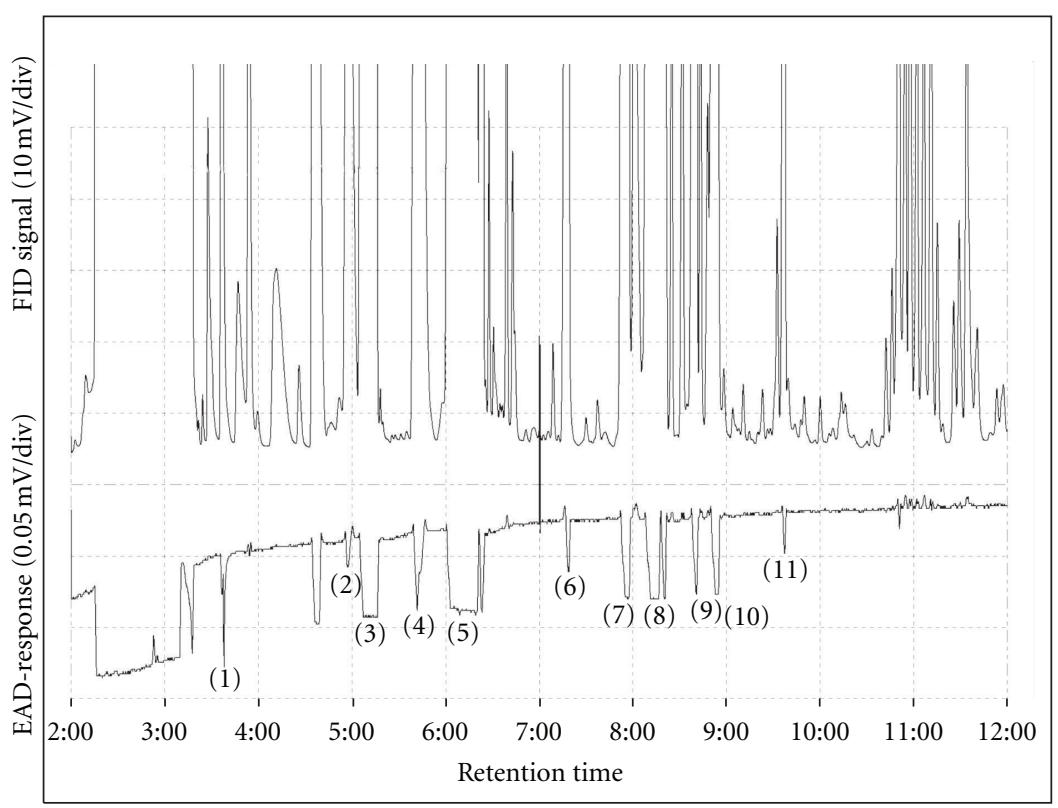

(a)

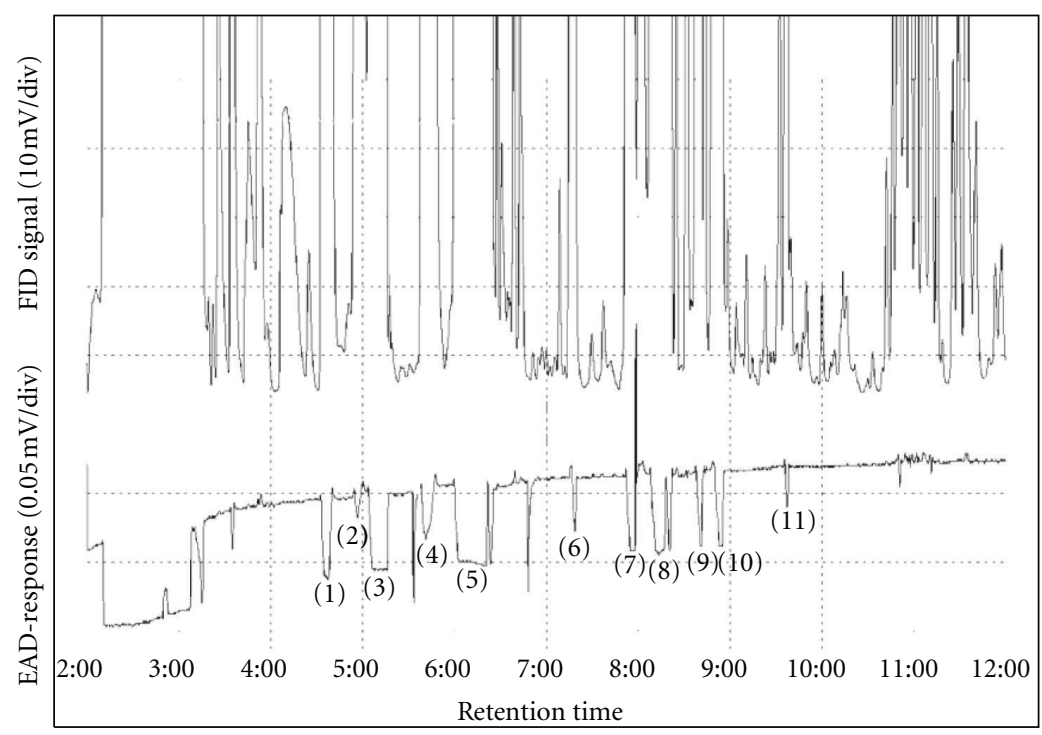

(b)

FIGURE 5: Eleven chemicals in fermented banana volatiles identified here, produced EAD-responses in olfactory organs of Morpho helenor. (a) Proboscis. (b) Foreleg, antenna, and midleg of Morpho helenor and the same organs of Caligo telamonius produced similar EADresponses. (1) 2-Methylpropyl acetate. (2) Ethyl butanoate. (3) Butyl acetate. (4) 1-Methylbutyl acetate. (5) 3-Methylbutyl acetate. (6) Isobutyl isobutyrate. (7) Butyl butanoate. (8) Hexyl acetate. (9) 1-Methylhexyl acetate. (10) Butyl 3-methylbutanoate. (11) Pentyl pentanoate.

The response-triggering chemical could be any of the ones that are present in the volatiles or a combination of two or more chemicals. In fact, a detected chemical could be attractive, repellent, or completely ignored by a butterfly. Hence, the next step to advance the understanding of this system will be securing (through synthesis or commercial acquisition) the individual banana semiochemicals that were identified by the present study, and conducting bioassays with these compounds. This will allow us to determine which compound(s) are responsible for butterfly attraction.

\section{Acknowledgments}

The authors thank Alexandra M. Shapiro, Ronald Rutowski, and Keith Willmott for their comments on the study and for offering many helpful suggestions. They thank the staff of the Florida Museum of Natural History, especially Jeffrey Hansen, Michael Boulware, and others at the Butterfly Rainforest for providing the facility for the experiment. They thank Peter Teal and others at the Chemistry Unit of the Center for Medical Agricultural and Veterinary Entomology 

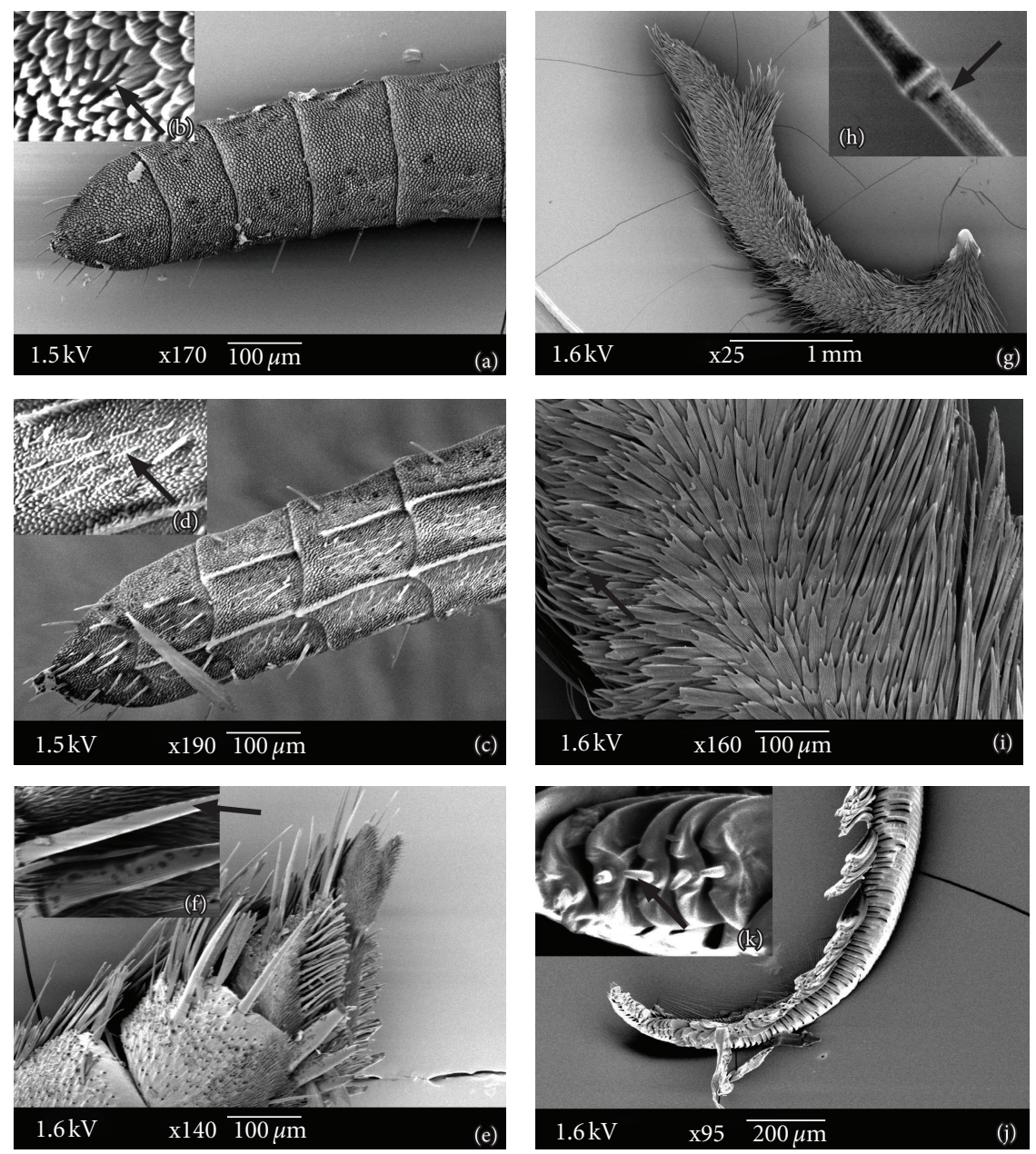

FIGURE 6: Scanning Electron Micrographs (SEMs) of Morpho helenor organs used for EAD analyses. (a-b) Antenna, dorsal surface. (c-d) Antenna, ventral surface. (e-f) Foreleg tip. (g-i) Labial palpus. (j-k) Galeae of proboscis. Closeup inserts show sensory organs potentially responsible for the observed $\mathrm{EAD}$ responses.

(USDA-ARS) for their support and assistance with the use of equipment. They would particularly like to thank Rebecca Blair for her help with the GC-EAD. Comments by the anonymous reviewers greatly improved the quality of the paper.

\section{References}

[1] S. L. Swihart, "The neural basis of colour vision in the butterfly, Papilio troilus," Journal of Insect Physiology, vol. 16, no. 8, pp. 1623-1636, 1970.

[2] A. D. Briscoe, G. D. Bernard, A. S. Szeto, L. M. Nagy, and R. H. White, "Not all butterfly eyes are created equal: rhodopsin absorption spectra, molecular identification, and localization of ultraviolet-, blue-, and green-sensitive rhodopsin-encoding mRNAs in the retina of Vanessa cardui," Journal of Comparative Neurology, vol. 458, no. 4, pp. 334-349, 2003.

[3] V. A. Lukhtanov, N. P. Kandul, J. B. Plotkin, A. V. Dantchenko, D. Haig, and N. E. Pierce, "Reinforcement of pre-zygotic isolation and karyotype evolution in Agrodiaetus butterflies," Nature, vol. 436, no. 7049, pp. 385-389, 2005.
[4] H. Ômura and K. Honda, "Priority of color over scent during flower visitation by adult Vanessa indica butterflies," Oecologia, vol. 142, no. 4, pp. 588-596, 2005.

[5] C. A. Swihart, "Colour discrimation by the butterfly Heliconius charitonius linn," Animal Behaviour, vol. 19, no. 1, pp. 156164, 1971.

[6] S. Hori, H. Takeuchi, K. Arikawa et al., "Associative visual learning, color discrimination, and chromatic adaptation in the harnessed honeybee Apis mellifera L," Journal of Comparative Physiology A, vol. 192, no. 7, pp. 691-700, 2006.

[7] M. Kinoshita, N. Shimada, and K. Arikawa, "Colour vision of the foraging swallowtail butterfly Papilio xuthus," Journal of Experimental Biology, vol. 202, no. 2, pp. 95-102, 1999.

[8] S. Andersson and H. E. M. Dobson, "Behavioral foraging responses by the butterfly Heliconius melpomene to Lantana camara floral scent," Journal of Chemical Ecology, vol. 29, no. 10, pp. 2303-2318, 2003.

[9] D. Blackiston, A. D. Briscoe, and M. R. Weiss, "Color vision and learning in the monarch butterfly, Danaus plexippus (Nymphalidae)," Journal of Experimental Biology, vol. 214, no. 3, pp. 509-520, 2011. 
[10] P. J. DeVries, T. R. Walla, and H. F. Greeney, "Species diversity in spatial and temporal dimensions of fruit-feeding butterflies from two Ecuadorian rainforests," Biological Journal of the Linnean Society, vol. 68, no. 3, pp. 333-353, 1999.

[11] F. Molleman, M. E. Van Alphen, P. M. Brakefield, and B. J. Zwaan, "Preferences and food quality of fruit-feeding butterflies in Kibale Forest, Uganda," Biotropica, vol. 37, no. 4, pp. 657-663, 2005.

[12] H. Ômura, K. Honda, K. Asaoka, and T. A. Inoue, “Tolerance to fermentation products in sugar reception: gustatory adaptation of adult butterfly proboscis for feeding on rotting foods," Journal of Comparative Physiology A, vol. 194, no. 6, pp. 545$555,2008$.

[13] J. H. Visser, "Host odor perception in phytophagous insects," Annual Review of Entomology, vol. 31, pp. 121-144, 1986.

[14] M. Giurfa and R. Menzel, "Insect Visual perception: complex abilities of simple nervous systems," Current Opinion in Neurobiology, vol. 7, no. 4, pp. 505-513, 1997.

[15] R. A. Raguso and M. A. Willis, "Synergy between visual and olfactory cues in nectar feeding by naïve hawkmoths, Manduca sexta," Animal Behaviour, vol. 64, no. 5, pp. 685-695, 2002.

[16] A. Balkenius, S. Bisch-Knaden, and B. Hansson, "Interaction of visual and odour cues in the mushroom body of the hawkmoth Manduca sexta," Journal of Experimental Biology, vol. 212, no. 4, pp. 535-541, 2009.

[17] S. Andersson and H. E. M. Dobson, "Antennal responses to floral scents in the butterfly Heliconius melpomene," Journal of Chemical Ecology, vol. 29, no. 10, pp. 2319-2330, 2003.

[18] S. Andersson, "Antennal responses to floral scents in the butterflies Inachis io, Aglais urticae (Nymphalidae), and Gonepteryx rhamni (Pieridae)," Chemoecology, vol. 13, no. 1, pp. 13-20, 2003.

[19] J. Li, R. Wakui, M. Horie et al., "Feeding stimulant in Cinnamomum camphora for the common bluebottle, Graphium sarpedon nipponum (Lepidoptera: Papilionidae)," Zeitschrift fur Naturforschung C, vol. 65, no. 9-10, pp. 571-576, 2010.

[20] J. Li, R. Wakui, S. I. Tebayashi, and C. S. Kim, "Volatile attractants for the common bluebottle, graphium sarpedon nipponum, from the host, cinnamomum camphora," Bioscience, Biotechnology and Biochemistry, vol. 74, no. 10, pp. 1987-1990, 2010.

[21] H. Fadamiro, L. Chen, C. Akotsen-Mensah, and W. N. Setzer, "Antennal electrophysiological responses of the giant swallowtail butterfly, Papilio cresphontes, to the essential oils of Zanthoxylum clava-herculis and related plants," Chemoecology, vol. 20, no. 1, pp. 25-33, 2010.

[22] R. Nishida, T. Ohsugi, S. Kokubo, and H. Fukami, "Oviposition stimulants of a Citrus-feeding swallowtail butterfly, Papilio xuthus L.," Experientia, vol. 43, no. 3, pp. 342-344, 1987.

[23] K. Honda, H. Ômura, M. Chachin, S. Kawano, and T. A. Inoue, "Synergistic or antagonistic modulation of oviposition response of two swallowtail butterflies, Papilio maackii and $P$. protenor, to Phellodendron amurense by its constitutive prenylated flavonoid, phellamurin," Journal of Chemical Ecology, vol. 37, no. 6, pp. 575-581, 2011.

[24] R. Nishida, "Oviposition stimulant of a zeryntiine swallowtail butterfly, Luehdorfia japonica," Phytochemistry, vol. 36, no. 4, pp. 873-877, 1994.
[25] H. Ono, R. Nishida, and Y. Kuwahara, "A dihydroxy-gammalactone as an oviposition stimulant for the swallowtail butterfly, Papilio bianor, from the rutaceous plant, Orixa japonica," Bioscience, Biotechnology and Biochemistry, vol. 64, no. 9, pp. 1970-1973, 2000.

[26] T. Nakayama, K. Honda, H. Ômura, and N. Hayashi, "Oviposition stimulants for the tropical swallowtail butterfly, Papilio polytes, feeding on a rutaceous plant, Toddalia asiatica," Journal of Chemical Ecology, vol. 29, no. 7, pp. 1621-1634, 2003.

[27] K. Honda, H. Ômura, N. Hayashi, F. Abe, and T. Yamauchi, "Conduritols as oviposition stimulants for the danaid butterfly, Parantica sita, identified from a host plant, Marsdenia tomentosa," Journal of Chemical Ecology, vol. 30, no. 11, pp. 2285-2296, 2004.

[28] H. Ono, Y. Kuwahara, and R. Nishida, "Hydroxybenzoic acid derivatives in a nonhost rutaceous plant, Orixa japonica, deter both oviposition and larval feeding in a rutaceae-feeding swallowtail butterfly, Papilio xuthus L," Journal of Chemical Ecology, vol. 30, no. 2, pp. 287-301, 2004.

[29] M. J. Scoble, The Lepidoptera-Form, Function And Diversity, Oxford University Press, 1992.

[30] P. Nagnan-Le Meillour, A. H. Cain, E. Jacquin-Joly et al., "Chemosensory proteins from the proboscis of Mamestra brassicae," Chemical Senses, vol. 25, no. 5, pp. 541-553, 2000.

[31] H. Ômura and K. Honda, "Feeding responses of adult butterflies, Nymphalis xanthomelas, Kaniska canace and Vanessa indica, to components in tree sap and rotting fruits: synergistic effects of ethanol and acetic acid on sugar responsiveness," Journal of Insect Physiology, vol. 49, no. 11, pp. 1031-1038, 2003.

[32] T. Ando, S. I. Inomata, and M. Yamamoto, "Lepidopteran sex pheromones," Topics in Current Chemistry, vol. 239, pp. 51-96, 2004 . 

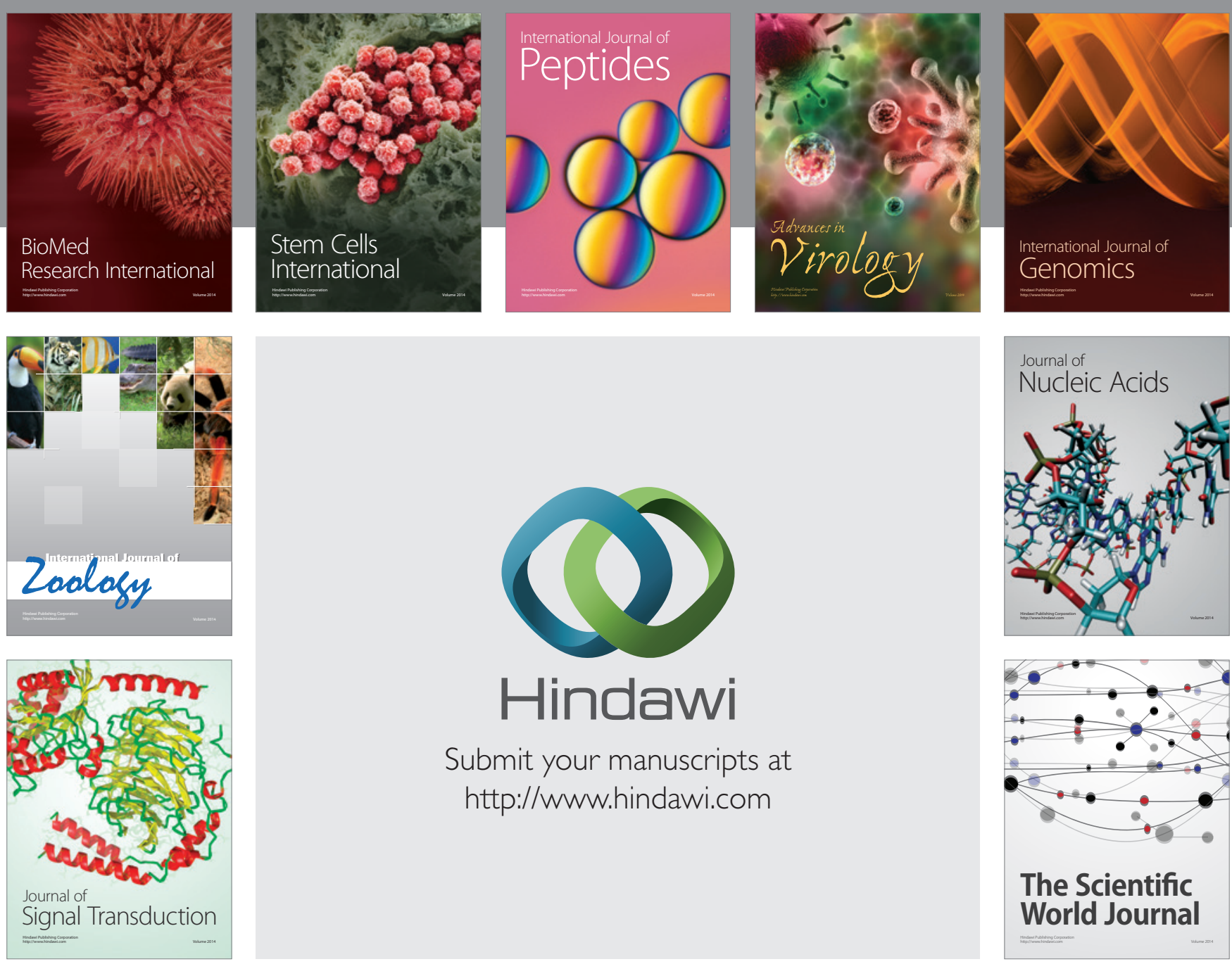

Submit your manuscripts at

http://www.hindawi.com
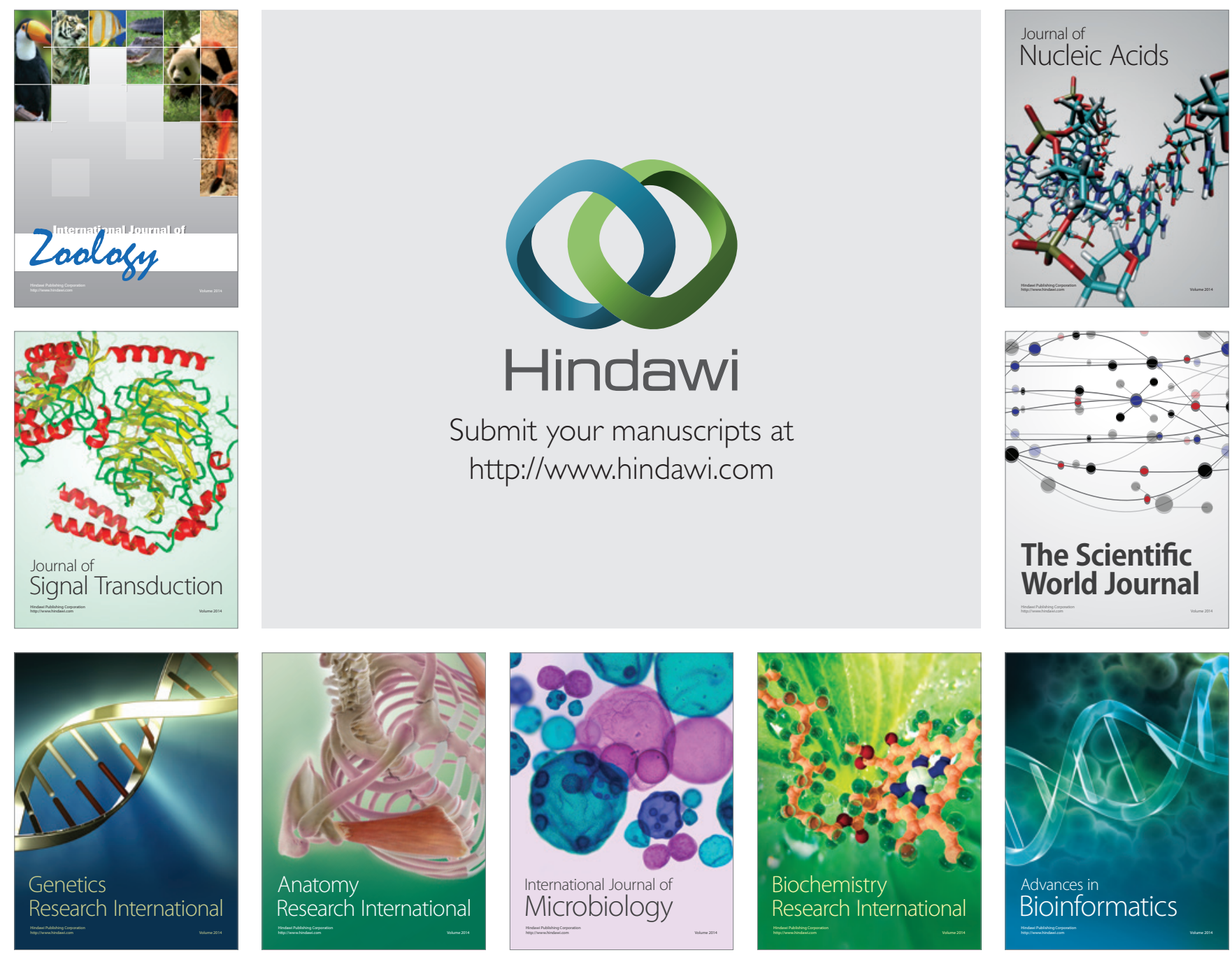

The Scientific World Journal
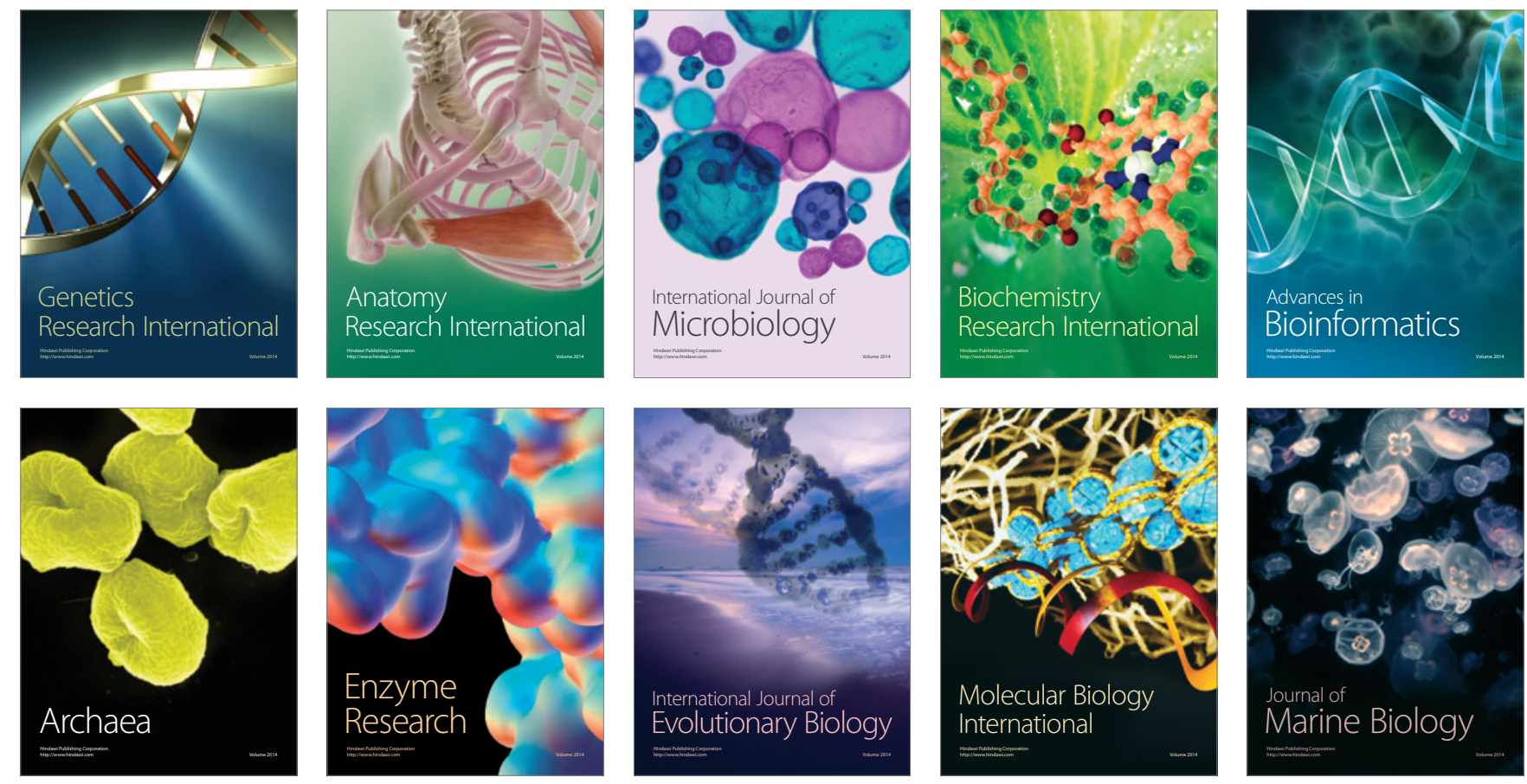